\title{
Drying Shrinkage of Mortar Incorporating High Volume Oil Palm Biomass Waste
}

\author{
Nor Hasanah Abdul Shukor Lim ${ }^{1 *}$, Mostafa Samadi ${ }^{1}$, Abdul Rahman Mohd. Sam ${ }^{2}$, Nur \\ Hafizah Abd Khalid ${ }^{1}$, Noor Nabilah Sarbini ${ }^{1}$, Nur Farhayu Ariffin ${ }^{3}$, Mohd Warid Hussin ${ }^{1}$, \\ and Mohammed A. Ismail ${ }^{4}$ \\ ${ }^{1}$ Department of Structure and Materials, Faculty of Civil Engineering, Universiti Teknologi Malaysia, \\ 81310 , Johor, Malaysia. \\ ${ }^{2}$ UTM Construction Research Centre, Institute for Smart Infrastructure and Innovative Construction, \\ Faculty of Civil Engineering, Universiti Teknologi Malaysia,81310, Johor, Malaysia. \\ ${ }^{3}$ Faculty of Civil Engineering and Earth Resources, Universiti Malaysia Pahang, Lebuhraya 8 Tun \\ Razak, 26300 Kuantan, Pahang, Malaysia \\ ${ }^{4}$ Civil and Construction Engineering Department, Faculty of Engineering and Science, Curtin \\ University Sarawak, CDT 250, 98009 Miri, Sarawak, Malaysia
}

\begin{abstract}
This paper studies the drying shrinkage of mortar incorporating oil palm biomass waste including Palm Oil Fuel Ash, Oil Palm Kernel Shell and Oil Palm Fibre. Nano size of palm oil fuel ash was used up to 80 $\%$ as cement replacement by weight. The ash has been treated to improve the physical and chemical properties of mortar. The mass ratio of sand to blended ashes was $3: 1$. The test was carried out using $25 \times 25 \times 160 \mathrm{~mm}$ prism for drying shrinkage tests and $70 \times 70 \times 70 \mathrm{~mm}$ for compressive strength test. The results show that the shrinkage value of biomass mortar is reduced by $31 \%$ compared with OPC mortar thus, showing better performance in restraining deformation of the mortar while the compressive strength increased by $24 \%$ compared with OPC mortar at later age. The study gives a better understanding of how the biomass waste affect on mortar compressive strength and drying shrinkage behaviour. Overall, the oil palm biomass waste can be used to produce a better performance mortar at later age in terms of compressive strength and drying shrinkage.
\end{abstract}

\section{Introduction}

Drying shrinkage is strain associated with loss of moisture from the mortar by evaporation of water or hydration of cement. The change in volume of the mortar is related to the volume of water lost. The loss of free water from mortar may induce shrinkage. As the hydration process of the mortar continues, the water in the small capillaries is reduced significantly [1]. The loss of the water may force mortar to shrink causing cracks that can adversely affect the structural performances [2]. If drying shrinkage is not considered

\footnotetext{
* Corresponding author: norhasanah@,utm.my
} 
during the design stage it may have negative effect on the durability and serviceability of mortar.

Few studies have been conducted to examine the effects of oil palm fuel ash (OPFA) on drying shrinkage [3-6]. The results showed that by increasing the unground OPFA percentage as partial cement replacement, the shrinkage increased slightly at later ages. However, the use of 10 to $30 \%$ finer POFA $(10 \mu \mathrm{m})$ as cement replacement reduced the drying shrinkage of concrete. This is due to the pore refinement, the transformation of large pores into fine pores, and reduced the loss of water, thus reducing the drying shrinkage [6]. The transformation of large pores into fine pores decreases the evaporation of water from concrete surface and thus reduces the drying shrinkage [7].

Therefore, exploring OPFA as nano material would create an advanced waste material in improving the performances of mortar. In this paper, high volume of OPFA with nano size was used as cement replacement up to $80 \%$ with addition of kernel shell and oil palm fibre. This helps to reduce the waste generation from palm oil plantation.

\section{Materials and Methods}

\subsection{Materials}

The cement used in this study is Ordinary Portland cement (OPC) Type I. OPFA was obtained from the burning of palm oil shell and husk (in equal volume). OPFA collected was treated and processed until nanoparticles size [8]. The chemical properties of OPC and nano POFA were shown in Table 1. The chemical composition shows that OPC is rich in Calcium Oxide $(\mathrm{CaO})$ content while nano OPFA is consisting of Silica Oxide $\left(\mathrm{SiO}_{2}\right)$. The Oil Palm Kernel Shell was crushed and used as sand replacement. The Oil Palm Fibre added was $7 \%$ by the volume of binder. The mortar incorporating the oil palm biomass waste was then known as biomass mortar $[9,10]$.

Table 1. Chemical composition of OPC and Nano POFA.

\begin{tabular}{ccc}
\hline Chemical composition (\%) & OPC & Nano POFA \\
\hline $\mathrm{SiO}_{2}$ & 16.40 & 69.30 \\
$\mathrm{Al}_{2} \mathrm{O}_{3}$ & 4.24 & 5.30 \\
$\mathrm{Fe}_{2} \mathrm{O}_{3}$ & 3.53 & 5.10 \\
$\mathrm{CaO}$ & 68.30 & 9.15 \\
$\mathrm{~K} 2$ & 0.22 & 11.10 \\
$\mathrm{MgO}$ & 2.39 & 4.10 \\
$\mathrm{CO}_{2}$ & 0.10 & 0.10 \\
$\mathrm{SO}_{3}$ & 4.39 & 1.59 \\
$\mathrm{LOI}$ & 2.40 & 1.30 \\
\hline
\end{tabular}

\subsection{Testing Procedures}

All mortar specimens were prepared with binder to fine aggregates with the ratio of 1:3, whereby the fine aggregates was prepared into saturated surface dried condition. The mixing was carried out in a room temperature. The mix proportions are based on volume of materials as according to BS EN 998-1:2010 [11]. The test specimens of $70 \times 70 \times 70 \mathrm{~mm}$ cubes were prepared as described in ASTM C109-13 [12]. The specimens were then cured in water until the age of testing. Mix proportion of OPC and biomass mortars were shown in Table 2. 
Table 2. Mix proportion of mortars $\left(\mathrm{kg} / \mathrm{m}^{3}\right)$.

\begin{tabular}{ccccccc}
\hline Mortar & Cement & Nano OPFA & Sand & OPKS & OPF & W/C ratio \\
\hline OPC & 525 & - & 1578 & - & - & 0.4 \\
Biomass & 105 & 420 & 789 & 789 & 3.7 & 0.4 \\
\hline
\end{tabular}

Drying shrinkage is strain associated with loss of moisture from the mortar by evaporation of water or hydration of cement. For drying shrinkage, the size of specimens was $25 \times 25 \times 250 \mathrm{~mm}$ as shown in Figure 1 and cured in water. The test was conducted according to ASTM C596-14 [13]. After demoulding, mortar specimens were measured and marked to get the centre of the specimens. The marked was necessary as a guide to place the demec disc and demec gauge for shrinkage reading. The demec disc was glued to both sides at a distance of $75 \mathrm{~mm}$ from the centre. After that, demec gauge was placed on the demec disc for 5 to 10 minutes and the initial readings were recorded. Shrinkage readings were recorded by using demec gauge at $25 \pm 2^{\circ} \mathrm{C}$. The drying shrinkage strain of each type of mortar was calculated. Shrinkage was determined as an average of three specimens. It was calculated by the following Equations 1:

$$
\text { Percentage of shrinkage }=\frac{L o-L}{L o} \times 100
$$

where $L_{o}=$ original length (length of standard bar) (mm); $L=$ length as measured during or after cure excluding studs ( $\mathrm{mm})$.

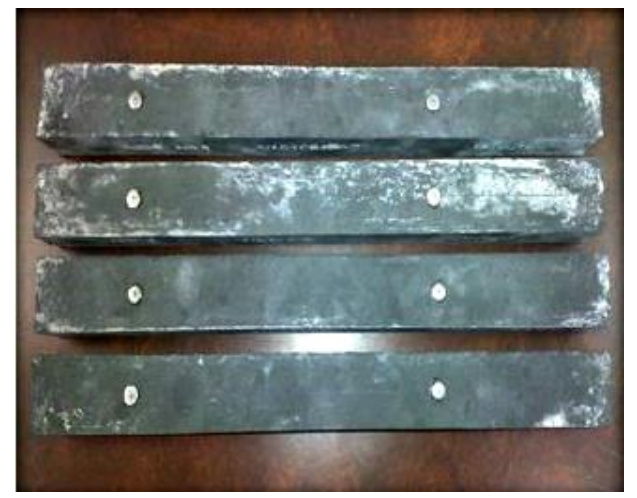

a) Specimens with demec disc glued.

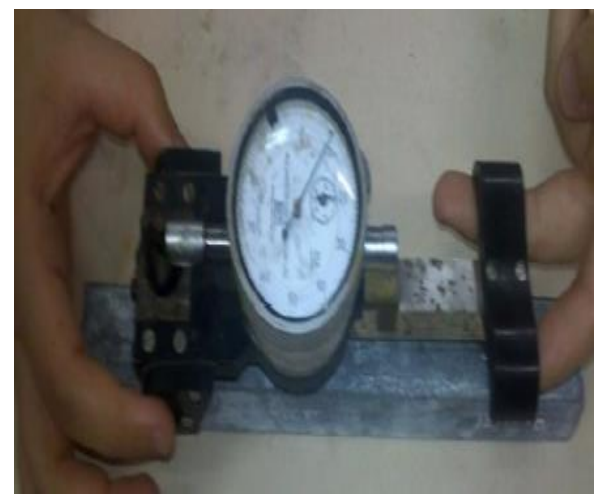

b) Measuring shrinkage using demec gauge.

Fig. 1. Sample preparation for drying shrinkage test.

\section{Results and Discussions}

\subsection{Compressive Strength}

Fig. 2 shows the compressive strength comparison of the OPC and biomass mortars. As the age of water curing increases, the compressive strength of OPC and biomass mortars are increases. This is due to the continuous hydration process and pozzolanic reaction occurred 
in the mortars. At 28 days curing, the compressive strength of biomass mortar increases by $24 \%$ as compared to OPC mortar. This is due to the second production of C-S-H gel from pozzolanic reaction. After 90 days of curing, the OPC and biomass mortars show compressive strength of $32.43 \mathrm{MPa}$ and $42.84 \mathrm{MPa}$, respectively. Despite the stronger bond produced and filler packing effect, the fibre in biomass mortar help to distribute the load and increase the bond between binder and fine aggregates resulting in an increase in the compressive strength. The compressive strengths obtained at the age of 90 days were approximately $24 \%$ higher than the target required design strength of $30 \mathrm{MPa}$. This continual increase in strength even after 90 days indicates that the biomass mortar keep increase the compressive strength through the gradual hydration process and pozzolanic reaction of the nano size OPFA.

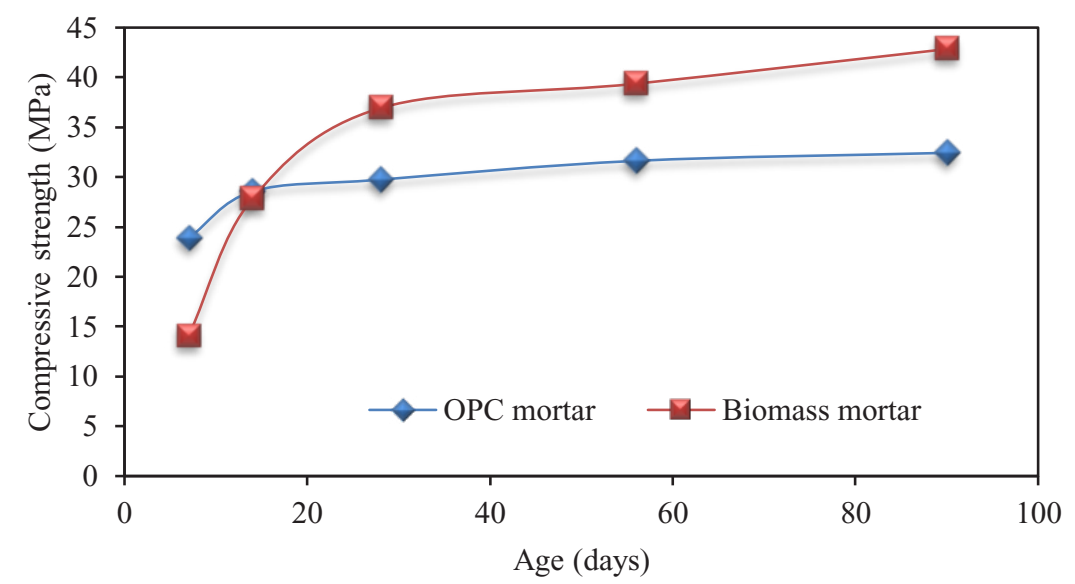

Fig. 2. Strength development of OPC and biomass mortars.

\subsection{Ultra Pulse Velocity}

Meanwhile, Fig. 3 shows the comparison of biomass and OPC mortars on the UPV values. The biomass mortar also produces lower UPV value at early age and increases as the hydration process increases. Despite the effect of nano OPFA as cement replacement in the biomass mortar, the smaller OPKS size with irregular and crushed particles increases the interlocking friction with the binder. In addition, the fibre content also increased the interlocking between fine aggregates and binder thus makes the biomass mortar denser and less porous. Since the void content in the mortar reduces, the UPV value is increases. Neville, (2011) reported that UPV value more than $4500 \mathrm{~m} / \mathrm{s}$ generally indicates mortar with excellent quality [14]. In this study, these excellent UPV values could be attributed to the improved pore structure of mortar as a result of optimum particle packing and enhanced filling ability of nano size OPFA. Furthermore, higher UPV values were obtained at later age which could be attributed to the increased densification of the paste resulting from secondary hydration of the reactive nano OPFA. Similar findings were reported by previous research using fly ash as pozzolanic material on the packing effect [15]. 


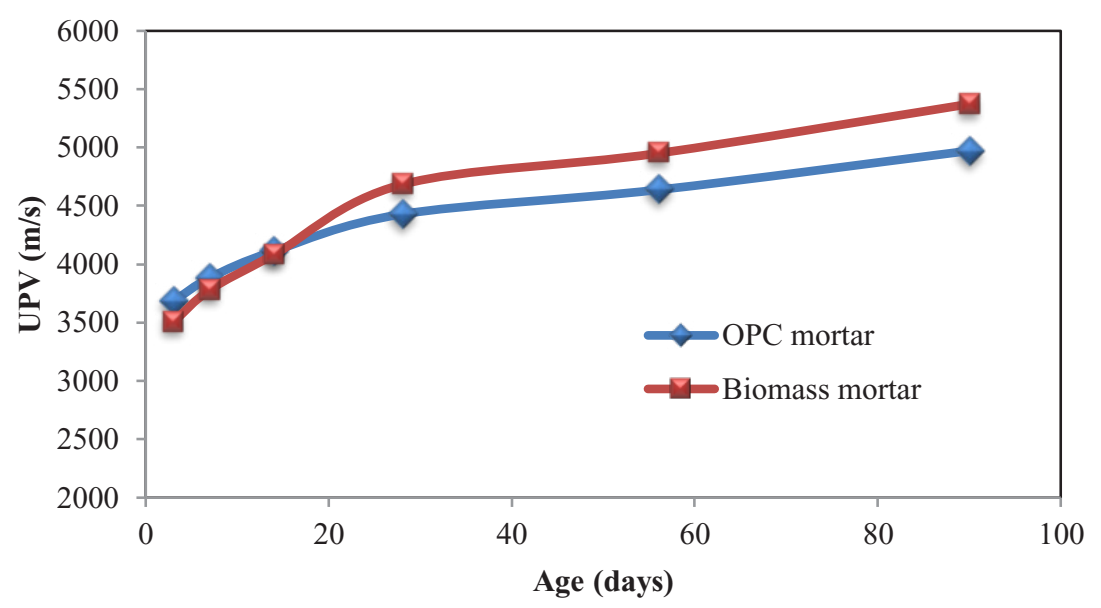

Fig. 3. UPV analysis of OPC and biomass mortars.

The UPV value and the compressive strength of biomass mortar have a strong and positive linear correlation as shown in Fig. 4. The coefficient of determination $\left(\mathrm{R}^{2}\right)$ value of $99 \%$ showed a good prediction of the relationship. The correlation was determined for the compressive strength values in the range of $13.63 \mathrm{MPa}$ to $47.37 \mathrm{MPa}$ and UPV value in the range of $3503 \mathrm{~m} / \mathrm{s}$ to $5373 \mathrm{~m} / \mathrm{s}$, respectively. Similar correlation was also observed by Demirboga et al., (2004) for the high strength concretes incorporating fly ash and blast furnace slag [16].

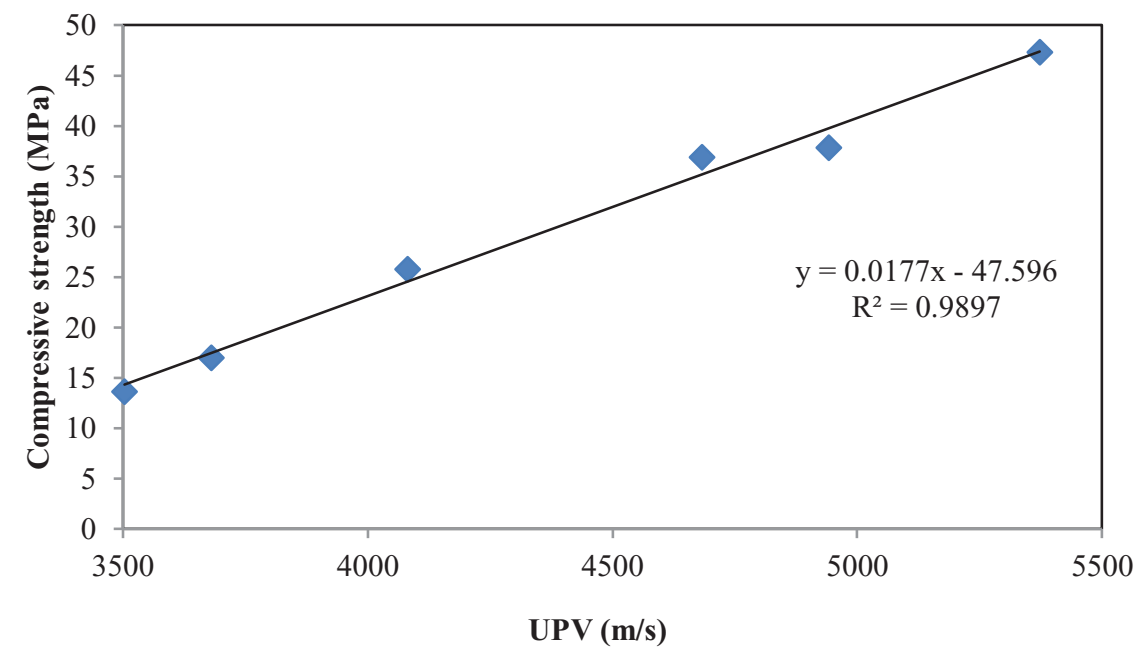

Fig. 4. Relationship between compressive strength and UPV value of biomass mortar. 


\subsection{Drying Shrinkage}

Fig. 5 shows the development of the drying shrinkage OPC and biomass mortars until the age of 90 days. As can be seen in the figure, the drying shrinkage of OPC mortar is higher than that of biomass mortar at all ages. The increasing rate of drying shrinkage of both mortars is very sharp in the first month. At the age of 28 days, the drying shrinkage for OPC and biomass mortars are $853 \times 10^{-6} \mathrm{~mm} / \mathrm{mm}$ and $621 \times 10^{-6} \mathrm{~mm} / \mathrm{mm}$, respectively. This is due to the dense structure from the gradual hydration process and pozzolanic reaction of nano OPFA as cement replacement [17]. In addition, the fibre content is found to have an effect in reducing the drying shrinkage of mortar. However, the shrinkage cracks were not observed because of the presence of fibres that prevented the occurrence of cracks thus reduces the shrinkage value. Similarly, previous research reported that the fibre content has a direct influence on restrained drying shrinkage in concrete, as well as on the control of cracking [18]. Therefore, by adding the NOPFA, OPKS and OPF, the shrinkage value of biomass mortar reduced by $31 \%$ from OPC mortar. Therefore, the results show that biomass mortar has better performance in deformation of mortar.

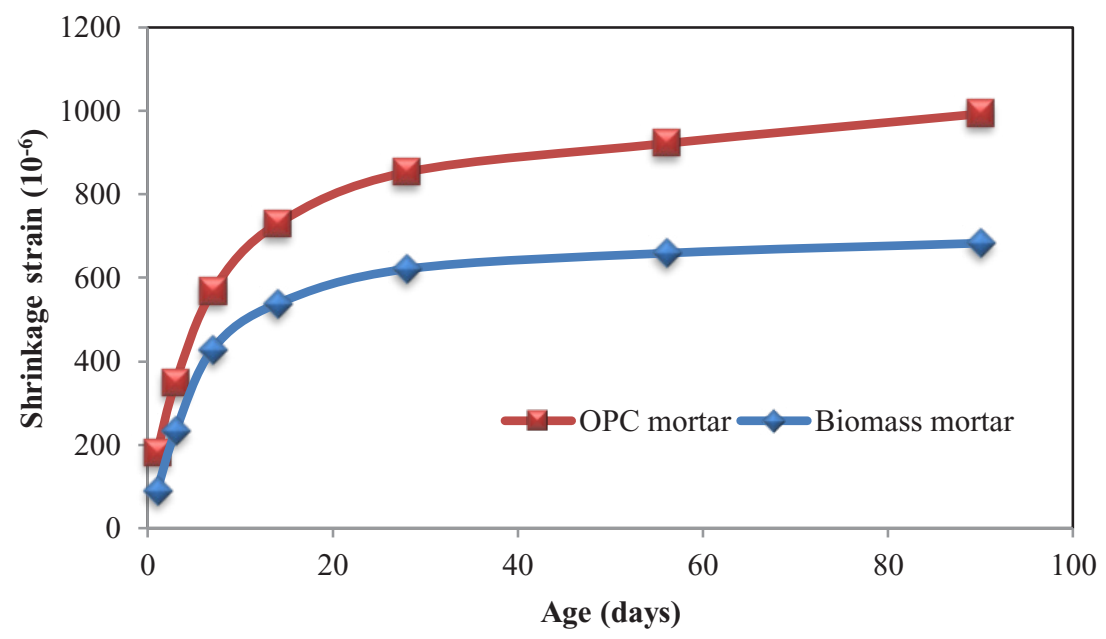

Fig. 5. Drying shrinkage of OPC and biomass mortars.

\section{Conclusions}

This study generally focuses on the performance of mortar using high volume waste from oil palm biomass. Higher values of ultrasonic pulse velocity were obtained by using finer nano OPFA at all ages due to denser microstructure of the mortar. Similar result was obtained when biomass mortar yielded higher UPV values by $5 \%$ compared with OPC mortar after 28 days. The UPV values at 28 days for biomass and OPC mortars are 4683 and $4429 \mathrm{~m} / \mathrm{s}$, respectively. Besides, the performance of biomass mortar in drying shrinkage which is $683 \times 10^{-6} \mathrm{~mm} / \mathrm{mm}$ is better than OPC mortar with a value of $993 \times 10^{-6}$ $\mathrm{mm} / \mathrm{mm}$ at the age of 90 days. With the addition of nano OPFA, OPKS and OPF, the shrinkage value of biomass mortar is reduced by $31 \%$ compared with OPC mortar thus, showing better performance in restraining deformation of the mortar. 
The authors are grateful to the Ministry of Higher Education, Malaysia (MOHE) and Research Management Centre (RMC), Universiti Teknologi Malaysia (UTM) for financial support under grant Q.J130000.2722.02K88. The authors are also thankful to the staff of Structures \& Materials Laboratory, Faculty of Civil Engineering and microstructure lab, Hanyang University Ansan Campus, South Korea for the support throughout the study.

\section{References}

1. W. Zhang, M. Zakaria and Y. Hama. Constr Build Mater 49, 500-510 (2013)

2. B.S. Thomas. Renewable and Sustainable Energy Reviews, 80, 550-561 (2017)

3. N. Ranjbar, A. Behnia, B. Alsubari, P.M. Birgani and M.Z. Jumaat. Journal of Cleaner Production 112, 723-730 (2016)

4. A.S.M.A. Awal and M.W. Hussin. Malaysian Journal of Civil Engineering 21(2),125134 (2009)

5. W. Tangchirapat and C. Jaturapitakkul. Cement Concrete Comp 32, 767-774 (2010)

6. W. Tangchirapat, C. Jaturapitakkul and P. Chindaprasirt, Constr Build Mater 23, 2641-2646 (2009)

7. N.H.A.S. Lim, M. Samadi, A. Shafagat, N.F. Ariffn, A. Keyvanfar and A.R.M. Sam. Journal of Environmental Treatment Techniques, 4(4), 149-152 (2016)

8. N.H.A.S. Lim, M.A. Ismail, H.S. Lee, M.W. Hussin, A.R.M. Sam and M. Samadi. Constr Build Mater 93, 29-34 (2015)

9. N.H.A.S. Lim, M.W. Hussin, A.R.M. Sam, M.A.R. Bhutta, N.F. Ariffn, N.H.A. Khalid and M. Samadi, Advanced Materials Research, 1113, 578-585 (2015)

10. H.L. Muttashar, M.W. Hussin, J. Mirza, N.H.A.S. Lim and G.F. Huseien, Jurnal teknologi 78(8), 101-108 (2016)

11. British Standard Institution. Specification for mortar for masonry. Rendering and plastering mortar. BS EN 998-1:2010 (2010)

12. ASTM C109. Standard test method for compressive strength of hydraulic cement mortars. Annual Book of ASTM Standards, American Society for Testing and Materials (2013)

13. ASTM C596. Standard test method for drying shrinkage of mortar containing hydraulic cement. Annual Book of ASTM Standards, American Society for Testing and Materials (2009)

14. A.M. Neville. Properties of Concrete (Fifth Edition). Harlow, England: Pearson Education Limited (2011)

15. J. Tangpagasit, R. Cheerarot, C. Jaturapitakkul and K. Kiattikomol, Cement and Concrete Research 35, 1145-1151 (2005)

16. R. Demirboga, I. Turkmen and M.B. Karakoc, . Cement Concrete Comp 34(12), 2329$2336(2004)$

17. W. Li, Z. Huang, T. Zu, C. Shi, W.H. Dua, S.P. Shah, Journal of Materials in Civil Engineering 28, 04015068 (2016)

18. Z. Ahmad, A. Ibrahim and P.M.D. Tahir, International Journal of Engineering Science and Technology, 2(5), 699-708 (2010) 